\title{
Bridging perspectives from remote sensing and Inuit communities on changing sea-ice cover in the Baffin Bay region
}

\author{
Walter N. MEIER, ${ }^{1}$ Julienne STROEVE, ${ }^{1}$ Shari GEARHEARD ${ }^{2}$ \\ ${ }^{1}$ National Snow and Ice Data Center/World Data Center for Glaciology, CIRES, University of Colorado, Boulder, \\ CO 80309-0449, USA \\ E-mail: walt@nsidc.org \\ ${ }^{2}$ Department of Geography, University of Western Ontario, London, Ontario N6A 5C2, Canada
}

\begin{abstract}
Passive microwave imagery indicates a decreasing trend in Arctic summer sea-ice extent since 1979. The summers of 2002-05 have exhibited particularly reduced extent and have reinforced the downward trend. Even the winter periods have now shown decreasing trends. At the local level, Arctic residents are also noticing changes in sea ice. In particular, indigenous elders and hunters report changes such as earlier break-up, later freeze-up and thinner ice. The changing conditions have profound implications for Arctic-wide climate, but there is also regional variability in the extent trends. These can have important ramifications for wildlife and indigenous communities in the affected regions. Here we bring together observations from remote sensing with observations and knowledge of Inuit who live in the Baffin Bay region. Weaving the complementary perspectives of science and Inuit knowledge, we investigate the processes driving changes in Baffin Bay sea-ice extent and discuss the present and potential future effects of changing sea ice on local activities.
\end{abstract}

\section{INTRODUCTION}

Sea ice in the Arctic plays an important role in climate by reflecting incoming solar radiation and acting as a barrier to heat, momentum and moisture transfer between the ocean and atmosphere. In addition, the sea ice is a crucial element in the lives of wildlife and human communities surrounding the Arctic Ocean, who have adapted behaviorally and physically to the polar conditions. Changes to sea-ice conditions also have implications for other marine-based activities and industries, such as fisheries, offshore oil and gas exploration and maritime shipping.

Arctic sea ice has shown a dramatic decrease in summer extent since the beginning of the passive microwave multifrequency satellite record in 1979. The summers of 2002-05 were particularly extreme (Stroeve and others, 2005). The end-of-summer sea-ice minimum (which occurs in September) set a record low of $5.96 \times 10^{6} \mathrm{~km}^{2}$ in 2002 , over $10^{6} \mathrm{~km}^{2}$ below the long-term (1979-2000) mean. This was followed by near-record low September extents in 2003 and 2004. September 2005 again set a new record of $5.56 \times 10^{6} \mathrm{~km}^{2}$, $400000 \mathrm{~km}^{2}$ below the previous record low in 2002 .

These hemispheric extremes have been reflected in the sea-ice conditions in Baffin Bay (Fig. 1), home to a number of Inuit communities who live along the coasts of Baffin Island and West Greenland and who have observed and been affected by changing sea-ice conditions in recent years. These communities have a strong connection to the land, waters and ice where they live. Local livelihoods are strongly linked to hunting, herding and fishing activities. Their success in these traditional activities requires detailed knowledge of the local environment and ecology. Indeed, Inuit observations are likely the most systematic and regular insight into the current status of environment and wildlife (NTI, 2005). In recent years, changes to the environment have not gone unnoticed in Arctic communities, including changes in the sea ice (e.g. Krupnik and Jolly, 2002; Huntington and Fox, 2004; Oozeva and others, 2004). Here we combine the observations from satellite remote sensing with the Inuit observations to obtain a more complete picture of the changes in Baffin Bay and to understand the impacts of the observed changes on the indigenous populations.

\section{BAFFIN BAY SEA-ICE CONDITIONS}

The sea-ice regime of Baffin Bay is dominated by first-year ice (ice that does not survive the summer melt season). Scattered areas of multi-year ice may exist as fast ice (ice that grows from the coast and does not drift with winds and currents) in protected inlets; also, multi-year ice is advected
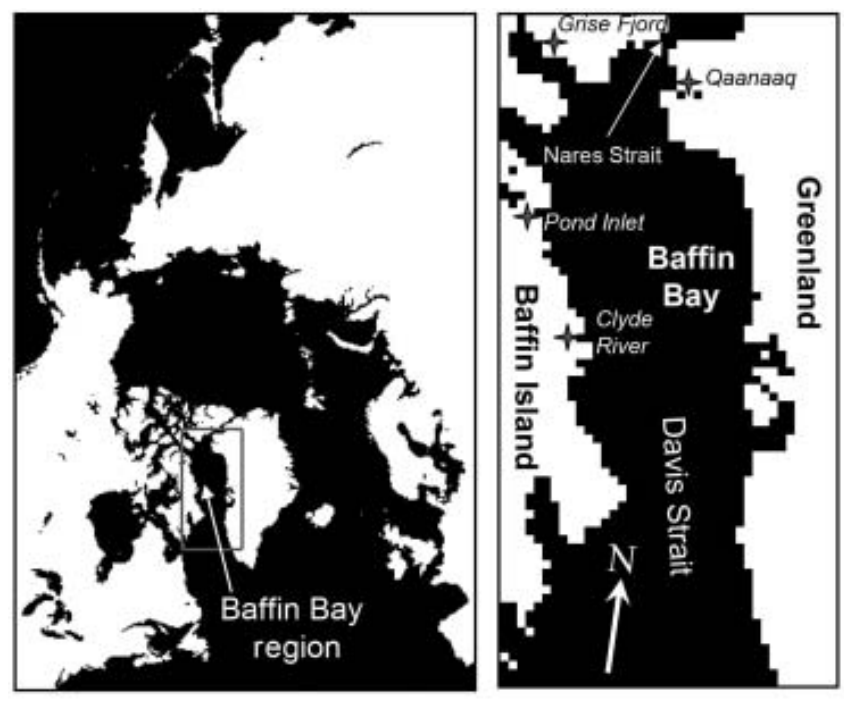

Fig. 1. Maps of study region. Left: Map of Arctic region, centered on the North Pole. The Baffin Bay region is outlined in gray. Right: The Baffin Bay region; the bay is bordered on the east by Greenland, on the west by Baffin Island, on the north by Nares Strait, and on the south by Davis Strait which empties into the Labrador Sea. The approximate location of Inuit communities discussed in this paper is indicated by stars with accompanying names in italic. 


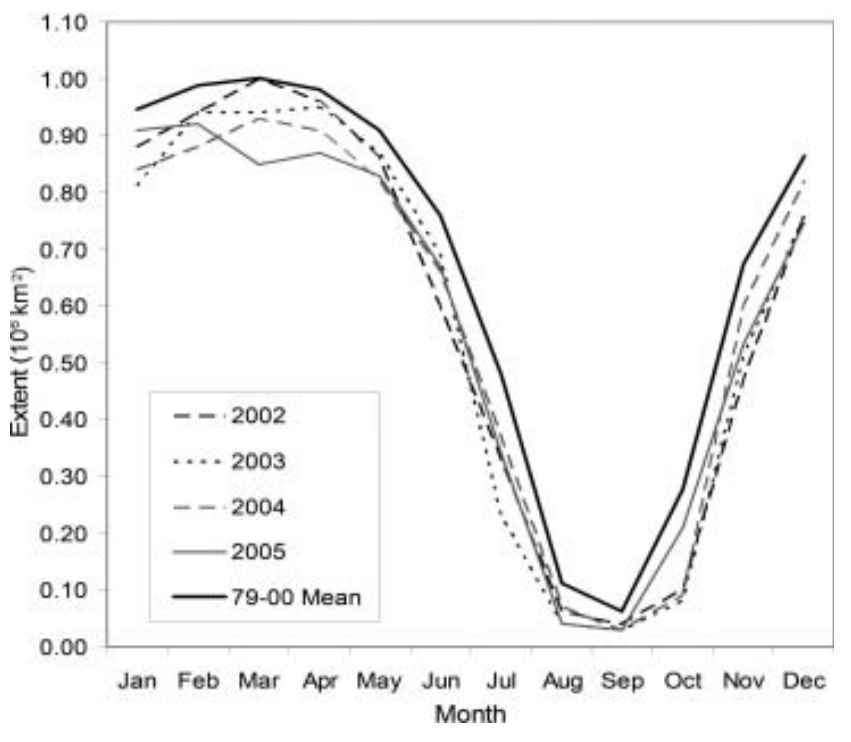

Fig. 2. Seasonal cycle of Baffin Bay sea-ice extent for the long-term (1979-2000) mean and 2002-05.

into the bay through Lancaster Sound, Smith Sound and other inlets through the Canadian Archipelago from the Arctic basin. Sea ice in the bay has a strong seasonal cycle, covering up $\sim 1.4 \times 10^{6} \mathrm{~km}^{2}$ during its maximum annual extent in February or March, but decreasing to near zero during the summer months of August and September. The ice is generally thin, with thicknesses of $0.5-1.5 \mathrm{~m}$ (Wadhams and others, 1985). Coastal regions are characterized by fast ice, but drifting pack ice is prevalent throughout most of the bay. The bay is a fairly dynamic region, with ice drift generally southward out of the bay (C. Fowler, http:// nsidc.org/data/nsidc-0116.html), due to both north winds that funnel through Nares Strait (see Fig. 1) and a southward current (except for a small north-flowing current along the west coast of Greenland). The northern end of the bay is characterized by a persistent area of open water, the North Water polynya, which is formed primarily due to the southward advection of sea ice away from an ice bridge that freezes over Nares Strait between Greenland and Ellesmere Island, though sensible heat likely plays a role as well (e.g. Barber and others, 2001). Icebergs that calve off glaciers in West Greenland are also common in the bay.

The Inuit have intimate knowledge of the small-scale character of sea ice, particularly fast ice, which is difficult to obtain from satellite remote sensing. High-resolution satellite and aircraft data can be used to infer certain small-scale features and characteristics (e.g. melt ponds, onset of melt/ freeze-up); however, they do not have the same long-term coverage (generations of knowledge), the ability to observe year-round in all weather or the ability to ground-truth. This makes Inuit knowledge an excellent complement to remotesensing research. For example, experienced hunters and elders can map the location of recurring leads and identify changes in those leads over time (e.g. Fox Gearheard, 2004). Remote sensing could do the same, but not over the same time period and without attendant knowledge that is critical to local livelihoods, such as how those leads are related to animal activity in the area or how changes in the leads have had an impact on various animal species or hunting patterns. Inuit knowledge and Inuit language add complementary layers to the ability of remote sensing, particularly by characterizing the features and processes of the fast-ice zone (tuvaq). Examples include knowledge of various features and processes of the icescape that contribute to safe or unsafe conditions, indicate the start or end of ice processes (e.g. break-up, refreezing of a lead) or indicate the likelihood of the presence of animals (e.g. evaluating ice for potential seal dens). Recent work around the Arctic is helping researchers learn more about local sea-ice terminology, knowledge and use (e.g. Fox, 2003; Aporta, 2004; George and others, 2004; Oozeva and others, 2004).

\section{SATELLITE DATA}

Sea-ice extent information was obtained from iceconcentration images derived from satellite passive microwave data acquired by the Nimbus 7 Scanning Multichannel Microwave Radiometer (SMMR), which operated from 1979 to 1987, and the Special Sensor Microwave/Imager (SSM/I). The latter has operated on a series of US Defense Meteorological Satellite Program (DMSP) satellites since 1987. Seaice concentration and extent (based on a 15\% concentration threshold) fields were derived from the imagery using the NASA-Team algorithm (Cavalieri and others, 1984) and were acquired from the National Snow and Ice Data Center (NSIDC) in Boulder, CO, USA (D.J. Cavalieri and others, http://nsidc.org/data/nsidc-0002.html). Monthly imagery and time-series data are available online at the NSIDC through the Sea Ice Index (http://nsidc.org/data/seaice_index/). The fields are produced on a $25 \mathrm{~km}$ polar stereographic grid. A $40 \times 80$ pixel $(1000 \times 2000 \mathrm{~km})$ subregion of Baffin Bay and surrounding inlets was selected for the analysis discussed here (Fig. 1).

Passive microwave imagery can successfully discriminate sea ice from ocean because sea ice is generally more emissive in the microwave frequencies than liquid water. However, due to the complexity of sea ice and its spatiotemporal variability, atmospheric effects (water vapor, liquid water) and surface effects (melting snow, refrozen snow, frost flowers), significant errors can occur in passive microwave sea-ice retrievals, particularly during melt and freeze-up periods and in regions of thin ice. In Baffin Bay, daily fields from the NASA-Team algorithm were found to underestimate concentration by an average of 5\% in winter and almost $15 \%$ in summer (Meier, 2005), with root-mean-square (rms) errors of $15-20 \%$. Monthly average fields are used here to reduce the rms error. Moreover, we focus on ice extent instead of ice concentration, because while the NASA-Team algorithm often underestimates concentration, it more accurately detects the simple presence of ice; thus a smaller bias is present in extent fields than in concentration. There is a great deal of interannual variability in the Baffin Bay ice cover due to the nature of the region, and a previous study found that long-term trends could not be detected above the year-toyear variability (Parkinson and others, 1999). However, that study was conducted before the recent extreme years, whose values fall outside the range of the interannual signal.

\section{SATELLITE OBSERVATIONS OF SEA-ICE CHANGES}

The monthly time series of Baffin Bay extents shows that all four years, 2002-05, were well below the long-term (19792000) mean throughout the seasonal cycle (Fig. 2). It appears that the anomalously low extents are primarily related to a later freeze-up in recent years. The rate of melt for 2002-05 
Table 1. Monthly sea-ice extent for long-term (1979-2000) mean and trend in extent for 1979-2005. There is not enough ice present during August and September to determine meaningful trends

\begin{tabular}{lccc}
\hline Month & $\begin{array}{c}\text { Mean extent } \\
10^{6} \mathrm{~km}^{2}\end{array}$ & $\begin{array}{c}\text { Std dev. } \\
10^{6} \mathrm{~km}^{2}\end{array}$ & $\begin{array}{c}\text { Trend } \\
\% \text { decade }^{-1}\end{array}$ \\
\hline Jan. & 0.95 & 0.07 & -3.6 \\
Feb. & 0.99 & 0.06 & -2.0 \\
Mar. & 1.00 & 0.05 & -2.5 \\
Apr. & 0.98 & 0.05 & -3.1 \\
May & 0.91 & 0.05 & -3.7 \\
June & 0.76 & 0.07 & -6.5 \\
July & 0.48 & 0.11 & -16.9 \\
Aug. & 0.11 & 0.07 & \\
Sept. & 0.06 & 0.04 & -23.8 \\
Oct. & 0.28 & 0.13 & -11.5 \\
Nov. & 0.67 & 0.10 & -6.0 \\
Dec. & 0.86 & 0.08 & \\
Ann. mean & 0.67 & 0.06 & \\
\hline
\end{tabular}

was similar to long-term mean; i.e. the downward slope of the extent in Figure 2 during the 2002-05 melt seasons was the same as the slope of the long-term mean. Melt onset did occur about 6 days earlier than the long-term mean (Stroeve and others, 2006), which is reflected in the lower spring extents (Fig. 2). However, the primary differences in the seasonal cycles are that freeze-up started an average of 9 days later in recent years (Stroeve and others, 2006) and was slower than previous years such that the 2002-05 October extents were as much as $200000 \mathrm{~km}^{2}(\sim 66 \%)$ lower over the long-term mean.

There is a downward trend in extent in all months (Table 1). The largest trends occur during summer (June, July) and during the beginning of freeze-up (October-December). The three months with the largest downward trends (July, October and November) are also those with the largest variability; this indicates that there may not be as much confidence in trends during these months, though we did not explicitly compute confidence levels.

The months of March, July and October are now discussed in more detail because of their importance in the seasonal cycle. March is the month in which the maximum extent occurs. July is the latest month in the melt season within which there is significant ice left in Baffin Bay. Finally, October is the month where significant freeze-up begins. July and October are also the months with the largest long-term variability (highest standard deviation) and the largest downward trends in extent (see Table 1).

All three months show a distinct downward trend since the mid-1990s (Fig. 3). The March values are the most stable over the long-term mean. However, each March since 2002 has been lower than the previous year (Figs 2 and 3); a similar 4 year downward trend occurred in 1983-86, but this was from a period of anomalously high extent towards 'normal' conditions; the 2002-05 trend began at nearaverage conditions and has descended into an anomalously low period. July shows much more variability than March, with low years typically followed by high years until 1996 . Starting in 1997, the July extent has been below the 19792000 mean, with a general downward trend although the extent rebounded somewhat in 2004 and 2005. October is

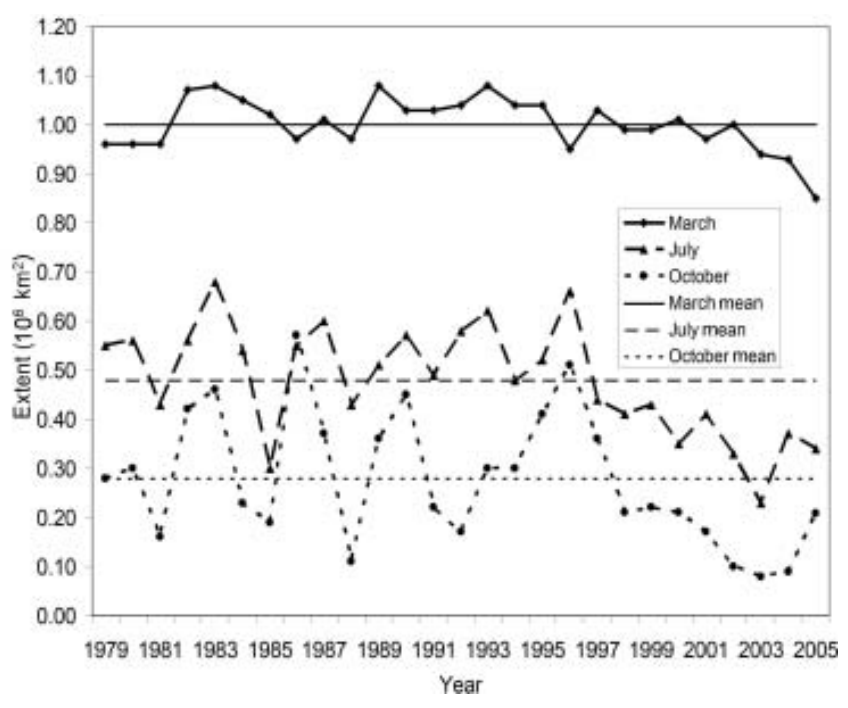

Fig. 3. Sea-ice extent for 1979-2005 for March, July and October. The long-term (1979-2000) mean for each of the three months is provided by the horizontal lines.

the month with the highest variability, but has a similar behavior to July, with low years followed the next year or the year after by high years up to 1997. Starting in October 1997, a downward trend to below-average extents began (though 1997 was still above normal in October); the trend finally substantially reversed in 2005, though the extent was still well below normal. The interannual variability also decreases substantially in both July and October, with much more consistent values from 1998 to 2005 compared to the previous 20 years.

The anomalously low extents in March, July and October are also clearly noticeable in maps of monthly sea-ice extent for the Baffin Bay region for 2002-05 compared to the longterm average (Fig. 4). These further illustrate the changes that have occurred. As mentioned above, the extent was near normal (but below average) in March 2002, with a progressive decrease in subsequent years. The extent in July is much reduced in 2002 and 2003, but exhibits something of a recovery in 2004 and 2005 (despite 2005 being a record low for extent over the entire Arctic (see http://nsidc.org/ data/seaice_index/)). The Octobers in 2002-04 show almost no ice in the bay, where normally the northern third is covered by ice at this time of the year; October 2005 shows some ice, but the extent is still much below normal. These low October extents again illustrate the delayed freeze-up seen in the time series (Fig. 2).

The decreased ice cover results from increased melt (thermodynamics), increased advection of ice out of the bay (dynamics) or a combination of the two factors. We have not investigated the relative contributions of each factor in detail. However, analysis of surface fields from the US National Oceanic and Atmospheric Administration (NOAA) Climate Diagnostics Center (CDC; http://www.cdc.noaa. gov/) indicates that the main influence is thermodynamic and not dynamic. Monthly mean surface air-temperature fields (not shown) from CDC show anomalously warm temperatures in all months for 2002-05 compared to a longterm (1968-96) mean. The warming is most pronounced during the spring (March) melt onset period and the fall (October-December) freeze-up. The anomalies are higher during the freeze-up than melt, again indicating that the 


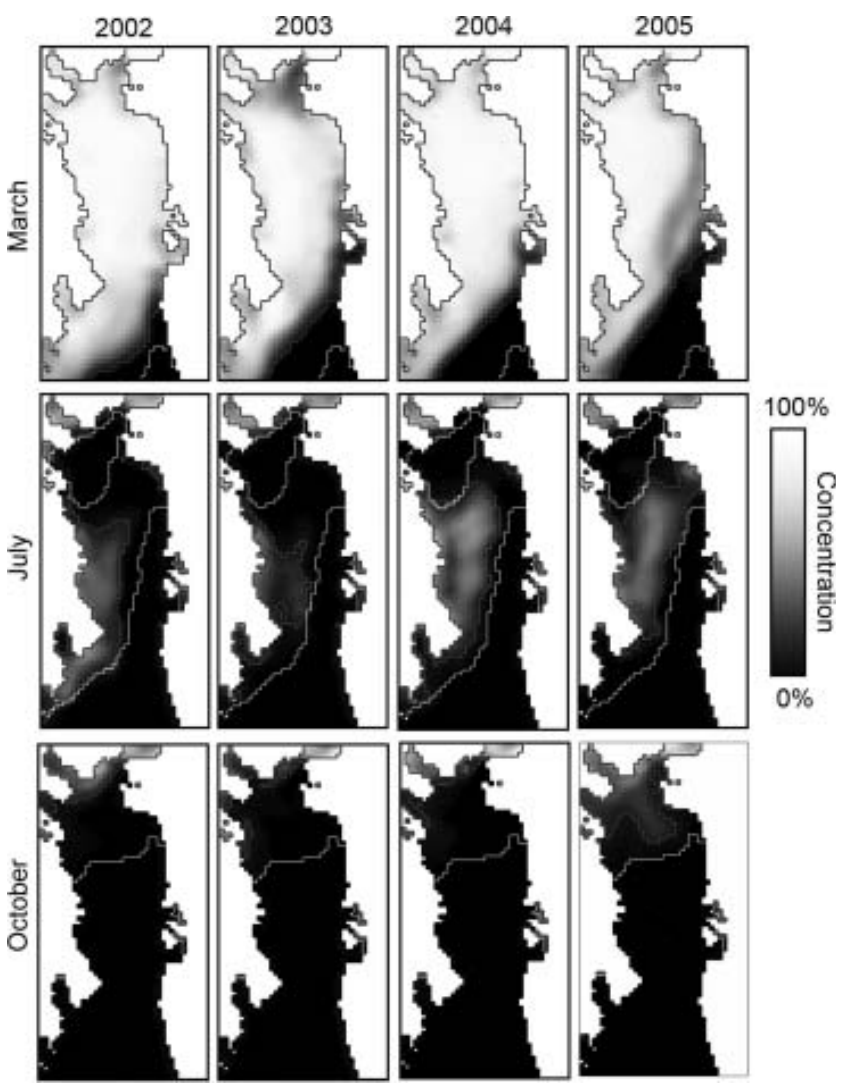

Fig. 4. SSM/I sea-ice concentration for March (top), July (middle) and October (bottom) for (from left to right) the years 2002-05. The 1979-2000 mean extent contour is white; the extent contour for each month is in grey. Sea ice varies from black (ocean) to white $(100 \%)$ ice. Land is in white with a black coastline.

major contributor is a slower freeze-up. Analysis of CDC sea-level pressure fields (not shown) indicates only small anomalies in all months for 2002-05, indicating that the atmospheric circulation, and hence ice drift, is not anomalous. Thus, thermodynamics is playing the major role. Another potential factor is the mode of the Arctic Oscillation (AO) during winter. However, the winter $\mathrm{AO}$ has generally been in a neutral state for 2002-05. Also, the AO primarily affects the atmospheric circulation (ice drift), which would be evident in the CDC sea-level pressure fields.

\section{INUIT OBSERVATIONS OF SEA-ICE CHANGES AND IMPACTS ON INUIT COMMUNITIES}

Remote sensing can provide useful general information about the sea-ice cover and its large-scale variability around Baffin Bay. High-resolution sensors, such as synthetic aperture radar and new laser altimetry technology, can provide finer-scale information on thickness, lead formation and ice deformation. However, these technologies are still new, can be difficult to interpret and have limited spatial and/or temporal coverage. Also, full insight into small-scale details of ice conditions cannot be gained from analysis of remote-sensing data alone (e.g. information on thickness, strength or stability). While ground-based observations cannot assess the large-scale extent and areal coverage available from satellites, the Inuit in this region have intimate knowledge of the ice and can provide complementary expert assessments of the state of the ice cover and changes in the ice.
In the Baffin Bay region, Inuit in both Canada and Greenland (Fig. 1) have noticed substantial changes in the ice cover. For example, in March 2005, Nunavut Tunngavik Inc. (NTI, the group responsible for implementing the Nunavut Land Claims Agreement) held a special workshop with elders from each Nunavut community, as well as researchers and government officials, to discuss climate change in Nunavut and challenges for adaptation. All but one of the 27 communities in Nunavut are located along the coast, and its residents depend on sea ice for travel and hunting. Sea ice was a key topic, and many observations of changes from around the territory (NTI, 2005) were shared, as described in Table 2. Sea-ice changes will have some positive impacts. For example, longer periods of open water will be a benefit to fisheries. Also, some wildlife species will likely benefit from less ice. However, Table 2 shows that, for the most part, recent ice changes have caused problems for communities and the wildlife they depend on.

Inuit emphasize that different environmental changes interact with each other to create new impacts, and that environmental changes interact with social and cultural changes (Fox, 2002; Fox Gearheard, 2004). Mushy sea ice creates rougher than usual sea ice, making travel conditions more difficult. The alterations to the environment also have a direct impact on the Arctic communities' assessment of risk. Sea-ice changes such as thinner ice and unusual leads create dangerous travel conditions, but these are compounded by unpredictable weather conditions and stronger winds that pack the snow too hard for the building of emergency igloos (GN, 2003; Fox Gearheard, 2004). Changing ice conditions also amplify the risks for inexperienced hunters (e.g. youth or 'weekend' hunters) who are neither as knowledgeable nor as equipped for normal conditions, never mind unpredictable ice and storms.

Newer technologies also play a role. Hunters use the global positioning system (GPS) and snow machines, which may freeze or be lost (in the case of GPS units), or break down, leaving inexperienced hunters stranded and in danger if they do not have the knowledge to navigate and survive on the ice using traditional methods. In fact, a number of hunters around Nunavut have lost valuable equipment through unexpected cracks or thin ice, an event that has severe consequences for a household dependent on that equipment to obtain food (NTI, 2005). Some of this risk is due to cultural effects (less knowledge transfer, too much reliance on technology and rescue services), but the unfamiliar state of the sea ice also likely plays a role. Thinner ice has even caused spring hunting to be stopped early in some areas along the Baffin coast (Fox Gearheard, 2004). Because of the changing ice conditions, many Inuit communities are rallying behind the idea of governmentsponsored insurance for hunting equipment and the development of equipment that floats.

Inuit have noticed significant changes in sea-ice processes and characteristics. One change that stands out in some of the Baffin Bay communities is that the sea ice is 'softer', 'mushy' or not as 'strong' as it used to be. Hunters from Pond Inlet, Clyde River and Grise Fjord (all in Nunavut; see Fig. 1) have observed that the sea ice used to have a flexible strength that they do not see anymore, and the new softer ice is not 'proper' sea ice (interviews with P. Aqiatusuk, L. Kakkee, A. Kautaq, C. Nutaraq and P. Sangoya, in GN, 2003). Inuit explain that a number of factors could be contributing to the soft sea-ice conditions. One is changing 
Table 2. Summary of changes in the sea ice and surrounding environment noted by Inuit, and the impacts on their lives (adapted from $\mathrm{NTI}, 2005)$

Changes in sea ice and environment

Sea ice generally thinner

Sea ice freezes up later and breaks up earlier

More open water leads to stronger and more erratic winds

Lack of ice is detrimental to health of polar bears

Melting/absence of multi-year ice near communities; icebergs moving out Stronger currents and more pronounced tides

Longer periods of open water
Examples of impacts from changes

Affects seal dens, seal-hole (aglu) hunting, floe-edge hunting

Subsistence hunting affected; seals do not fully molt before break-up, so seal skins are not as good quality; seals spend more time in the water, resulting in skinnier seals (for polar bears and humans who hunt them)

Greater danger during freeze-up and break-up; navigation in boats is more difficult

Incidents with polar bears increasing; more 'problem bears'

Calming effect on surface waters lost; source of fresh water lost

Coastal erosion; navigation in boats more difficult

Increased potential for commercial fisheries winds which blow more snow onto forming sea ice during freeze-up. Increased snowfall and higher rates of divergence may also be playing a role. Snow mixes with sea water to create a lard-like mix called punnirujuk (interview with A. Kautaq in GN, 2003). When that mix freezes up, the result is a weaker, softer ice. Experienced hunters can detect this kind of sea ice during and after freeze-up by striking the sea ice with a harpoon. Sea ice should feel a certain way when it is struck, a test only an experienced hunter can make, and this test has revealed that in recent years the sea ice along the Baffin coast is soft and of poor quality in many areas (interview with P. Sangoya in GN, 2003; interview with A. Qaqqaqiq in Fox Gearheard, 2004). As A. Qaqqaqiq from Clyde River explains:

'The texture of the sea ice is softer now. We use harpoons to break the sea ice with, the ice is softer because it doesn't seem to freeze as hard as it used to. I have known the sea ice all my life and the condition of it. Today, there is more packed ice, crumbled, the condition of it was not like that before. Today, there is more packed ice, more than there used to be. Back in the time when we traveled by dog team [ 1960s and earlier], the sea ice used to freeze more smoothly and more evenly, though there still are times when it freezes smoothly.' (interview in GN, 2003)

It is possible that this punnirujuk is related to the late freezeup seen in the satellite observations, as both are influenced by wind and temperature patterns. Also, the occurrence of punnirujuk during freeze-up contributes to the earlier spring melt. This concurs with satellite-derived melt-onset fields (Stroeve and others, 2006). For example, like Stroeve and others (2005), Inuit in Clyde River have observed that breakup is about 0.5 months earlier than normal (H.P. Huntington and others, unpublished information). The poorer-quality sea ice breaks up more easily (Fox Gearheard, 2004). Also, thinner sea ice which is observed in many areas breaks up sooner, and changing wind patterns have also contributed. Meltwater ponds have also been showing different characteristics in the soft ice conditions of recent years. According to an elder from Pond Inlet, meltwater ponds used to be very hard and slippery at the bottom (ice surface) during the melt period, but now they merge into the mushy ice texture (interview with P. Sangoya in GN, 2003).

Communities in Greenland have also been experiencing recent sea-ice changes. For example, in January 2002 the outermost hunting grounds off Qaanaaq were not covered by sea ice because of shifting wind conditions and ocean currents, whereas local hunters had utilized these areas up until the late 1990s (U. Qujaukitsoq, quoted in Huntington and Fox, 2004). At Qaanaaq, sea-ice conditions have changed over the last 5-6 years. The ice is generally thinner and is slower to form off the smaller forelands. The appearance of aakkarneq (ice thinned by ocean currents) occurs earlier in the year than normal. Also, sea ice (fast ice), which previously broke up gradually from the floe-edge towards land, now breaks off all at once (U. Qujaukitsoq, quoted in Huntington and Fox, 2004).

\section{CONCLUSION}

Passive microwave observations indicate a downward trend in the annual average Baffin Bay sea-ice cover at a rate of $6 \%$ decade $^{-1}$ from 1979 through 2005, with larger trends during the melt and freeze-up seasons. This is consistent with trends observed over the entire Arctic (Stroeve and others, 2005). Moreover, the past 4 years have experienced particularly low ice extents in Baffin Bay, again mirroring the Arctic as a whole. Recent years, since 1998, are also characterized by reduced interannual variability, with the region experiencing persistently below-normal ice cover instead of oscillating between higher and lower than normal conditions.

While the remote-sensing data presented provide a broad-scale overview of recent changes in the sea-ice cover of Baffin Bay, Inuit communities who live on the coast and rely on the sea ice for their livelihood can provide complementary insight and details on the finer-scale changes. They also provide a longer historical perspective. The changes noted by the Inuit have been substantial. Not only is there less ice cover, but, for example, the ice has become 'softer' and less stable. The Inuit can also provide information on other conditions contributing to the changes in the ice cover, such as changes in winds and snowfall. Atmospheric models provide quantitative information on such changes, but not at the local scale that the Inuit provide. Also, while quantitative, there are many uncertainties in such model estimates due to limitations of model parameterizations and forcing fields.

Sea-ice changes have had significant impacts on the Inuit, including their hunting activities, equipment loss, and safety while out on the ice. Inuit are very adaptable and so far have been able to cope with environmental changes. However, if 
sea-ice and other environmental changes continue at a rapid rate, there may be limits to this adaptability. Their observations can help put the satellite observations in context and illustrate the impacts of the changes on local communities. For example, the Inuit observations can provide small-scale information on the quality of the ice (e.g. hard, soft, mushy) and demonstrate how these changes impact their daily activities. Satellite information can potentially benefit the Inuit communities by providing information beyond their local area and aid in forecasting conditions and better planning for safer excursions onto the ice. Whether the changes seen in recent years in Baffin Bay and the Arctic region as a whole will continue or whether conditions will return to historical norms, the combination of satellite remote-sensing data and traditional Inuit knowledge will provide essential and complementary information for understanding the polar environment.

\section{ACKNOWLEDGEMENTS}

Passive microwave sea-ice fields were obtained from the NSIDC. This research was supported by the NASA Distributed Active Archive Center (DAAC) and the Naval Research Laboratory (grant No. N00173-04-P-6210). S. Gearheard gratefully acknowledges the Inuit for working with her over the years and generously sharing their knowledge. Research cited in this paper was supported by the US National Science Foundation (OPP 9906740, BE/CNH 0308493) and a doctoral fellowship from the Social Science and Humanities Research Council of Canada.

\section{REFERENCES}

Aporta, C. 2004. Routes, trails and tracks: trail-breaking among the Inuit of Igloolik. Études Inuit Studies, 28(2), 9-38.

Barber, D., R. Marsden, P. Minnett, G. Ingram and L. Fortier. 2001. Physical processes within the North Water (NOW) polynya. Atmos.-Ocean, 39(3), 163-166.

Cavalieri, D.J., P. Gloersen and W.J. Campbell. 1984. Determination of sea ice parameters with the NIMBUS 7 SMMR. J. Geophys. Res., 89(D4), 5355-5369.

Fox, S. 2002. "These are things that are really happening": Inuit perspectives on the evidence and impacts of climate change in Nunavut. In Krupnik, I. and D. Jolly, eds. The Earth is faster now: indigenous observations of Arctic environmental change.
Fairbanks, AK, Arctic Research Consortium of the United States, $12-53$.

Fox, S. 2003. When the weather is uggianaqtuq: Inuit observations of environmental change. Boulder, CO, University of Colorado, Boulder. Cartography Laboratory. Distributed by National Snow and Ice Data Center (NSIDC) and Arctic System Sciences (ARCSS). CD-ROM.

Fox Gearheard, S. 2004. When the weather is uggianaqtuq: linking Inuit and scientific observations of recent environmental change in Nunavut, Canada. ( $\mathrm{PhD}$ thesis, University of Colorado, Boulder.)

George, J.C., H.P. Huntington, K. Brewster, H. Eicken, D.W. Norton and R. Glenn. 2004. Observations on shorefast ice dynamics in Arctic Alaska and the responses of the Iñupiat hunting community. Arctic, 57(4), 363-374.

Government of Nunavut (GN). 2003. Inuit knowledge of climate change, North Baffin: a sample of Inuit experiences of recent climate and environmental changes in Clyde River, Pond Inlet, Resolute, Grise Fjord, Nunavut. Iqaluit, Nun., Government of Nunavut. Environmental Protection Services.

Huntington, H.P. and S. Fox. 2004. The changing Arctic: indigenous perspectives. In Arctic Climate Impact Assessment (ACIA), Arctic climate impact assessment: scientific report. Cambridge, etc., Cambridge University Press, 61-98.

Krupnik, I. and D. Jolly. 2002. The Earth is faster now: indigenous observations of Arctic environmental change. Fairbanks, AK, Arctic Research Consortium of the United States.

Meier, W.N. 2005. Comparison of passive microwave ice concentration algorithm retrievals with AVHRR imagery in Arctic peripheral seas. IEEE Trans. Geosci. Remote Sens., 43(6), 1324-1337.

Nunavut Tunngavik Inc. (NTI). 2005. What if the winter doesn't come? Inuit perspectives on climate change adaptation challenges in Nunavut. Iqaluit, Nun., Nunavut Tunngavik Inc.

Oozeva, C., C. Noongwook, G. Noongwook, C. Alowa and I. Krupnik. 2004. Watching ice and weather our way. Washington, DC, Smithsonian Institution; Savoonga, AK, Savoonga Whaling Captains Association.

Parkinson, C.L., D.J. Cavalieri, P. Gloersen, H.J. Zwally and J.C. Comiso. 1999. Arctic sea ice extents, areas, and trends, 1978-1996. J. Geophys. Res., 104(C9), 20,837-20,856.

Stroeve, J.C. and 6 others. 2005. Tracking the Arctic's shrinking ice cover: another extreme September minimum in 2004. Geophys. Res. Lett., 32(4), L04501. (10.1029/2004GL021810.)

Stroeve, J., T. Markus, W. Meier and J. Miller. 2006. Recent changes in the Arctic melt season. Ann. Glaciol., 44 (see paper in this volume)

Wadhams, P., A.S. McLaren and R. Weintraub. 1985. Ice thickness distribution in Davis Strait in February from submarine sonar profiles. J. Geophys. Res., 90(C1), 1069-1077. 